\title{
EXPLOITATION OF COUNTRYWIDE AIRBORNE LIDAR DATASET FOR DOCUMENTATION OF HISTORICAL HUMAN ACTIVITIES IN COUNTRYSIDE
}

\author{
Petr DUŠÁNEK \\ Charles University in Prague, Faculty of Science \\ Albertov 6, Prague 2, Czech Republic \\ p_dusanek@centrum.cz
}

Keywords: ALS, DTM, Shaded Relief

\begin{abstract}
During three years $(2010$ - 12) The Czech Office for Surveying, Mapping and Cadastre in cooperation with The Ministry of Defense of the Czech Republic and The Ministry of Agriculture of the Czech Republic are providing mapping of the entire area of the Czech Republic by Airborne laser scanning (ALS) technology. The goal of this project is to derive a highly accurate Digital Terrain Model (DTM) for purposes of administration like detection of flooded areas, orthorectification of areal images etc. Such data set also seems to be an interesting data source for mapping of human activities in countryside. Human settlements, agriculture or mining activities left significant scars on natural landscape. These significant man-made structures are a part of so called cultural landscape. Man-made structures include ancient settlements, remains of medieval mining activities or remains of settlements abandoned during $20^{\text {th }}$ century. This article generally presents how to derive information about the man-made structures from raw LiDAR. Examples of significant findings of man-made imprints in countryside are also presented. Goal of this article is not to describe a certain archeological site but to inform about strengths of ALS data to map human activities in countryside, mainly in forested areas.
\end{abstract}

\section{INTRODUCTION}

\subsection{Project of New Elevation Mapping of Czech Republic}

Since spring 2010 the entire area of the Czech Republic is mapped by technology of Airborne Laser Scanning (ALS). Investors of this project are the Czech Office for Surveying, Mapping and Cadastre, the Ministry of Defense and the Ministry of Agriculture of the Czech Republic. The Czech Office for Surveying, Mapping and Cadastre organizes and coordinates the project and is responsible for data processing from $3 / 4$ of the area of the Czech Republic. The Ministry of Defense provides data acquisition and capacity for processing of data from $1 / 4$ of the area. The Ministry of Agriculture is contributed with resources for the ALS system leasing. For the data acquisition the Czech Republic is divided into 3 parts (see Figure 1). The first one ("central zone") was covered in 2010, the "zone west" is being scanned in 2011 and the "zone east" will be scanned in 2012. Parameters of the scanning have been set to gain a Point Cloud with a density about 1 point $/ \mathrm{m}^{2}$ and with side overlap of adjacent strips about $50 \%$. There exist two sets of projects: one for spring seasons and one for vegetation seasons. During the spring seasons an average flying height is approximately $1400 \mathrm{~m}$ above ground level and a distance of flight lines is about $830 \mathrm{~m}$. During the vegetation seasons an average flying height is approximately $1200 \mathrm{~m}$ above ground level and a distance of flight lines is about $715 \mathrm{~m}$.

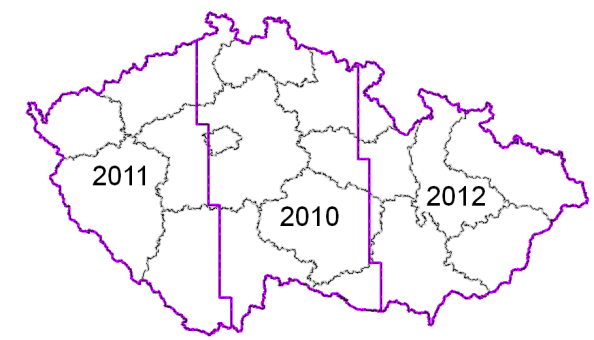

Figure 1: Division of the Czech Republic for data acquisition 


\subsection{Airborne Laser Scanning}

Airborne Laser Scanner, also called LiDAR, is an active remote sensing sensor (like RaDAR). Difference between RaDAR and LiDAR is wavelength of used electromagnetic radiation. LiDAR is working in visible or near infrared spectrum [1]. The basic principle of ALS is measuring of distance between sensor and point on ground [2]. The distance is measured by transit time of laser beam. By emission of laser pulse measurement of time is started, pulse hits measured surface and returns back. Then the measurement of transit time is ended [3]. By this definition it is clear that the distance between sensor and measured point is $1 / 2$ of the transit time multiplied by the speed of light. The accuracy of measured time is crucial for accuracy of distance measuring. Airborne Laser Scanner System consists of a laser distance meter unit, an opto-mechanical scanner and a processing \& control unit [4]. The laser distance meter unit consists of a laser emitter, clocks for measuring transit time and an electro-optical receiver. The opto-mechanical scanner provides emitting laser pulse across a flight direction. The processing \& control unit consists of a data recorder and a GNSS/IMU system, which is necessary for georeferencing the measurements into the reference coordinate system (WGS84).

\subsection{ALS data processing}

Processing of ALS data is divided into three main phases. The first phase so called Preprocessing consists of separation discrete echoes which represent measured surfaces. In the project mentioned above, a full-waveform scanner RIEGL LMS 680 is used. Digitizing of full-wave form ALS data (separation of discrete echoes) is a process of modeling the waveform as series of Gaussian distribution functions [5]. The next part of the Preprocessing is Georeferencing of ALS data using two inputs: digitized ALS data and flight trajectory. Flight trajectories are reconstructed from on-board GNSS/IMU data corrected by ground GNSS base station data. The last part of the Preprocessing phase is a Strip Adjustment, which is a process of relative orientation of neighbouring flying strips eliminating residual errors in ALS data. The Strip Adjustment is done by matching of tie objects (tie planes) in overlapping areas [6]. The output of the Preprocessing is a Point Cloud which is a large set of mass 3D points. Each point can also carry some additional information (intensity, GNSS Time, etc.). The Point Cloud contains a mixture of ground points and points lying on objects above bare Earth. The process of separation of ground and non-ground points is called Filtration. There are several filtering algorithms which are described and compared in [7]. The robust filtering algorithm (used in the project mentioned in 1.1) is iteratively leveling down the reference surface. Points too high above the reference surface are sorted out and they do not affect height of the reference terrain in next step. Automatic filtering of ALS data is quite successful but manual checking and editing of errors is still necessary. Digital Terrain Models (DTM) can by derived from ground points. DTMs have a form of a regular grid or an irregular triangular network (TIN).

\section{ALS DERIVATES SUITABLE FOR ARCHEOLOGICAL PROSPECTION}

\subsection{Digital Terrain model}

Digital Terrain model (DTM) is a 3-D representation of terrain including natural structures (hills, valleys etc.). Highly accurate and detailed DTMs include also man-made structures permanently changing character of natural terrain. Such man-made structures include linear transportation objects like road and railroad causeways, rock fill dams etc. Distinctness of a man-made structure in DTM depends on its size and its age. DTM generally exists in two forms, grid (Figure 2 a) and TIN (Figure 2 b). The advantage of regularly spaced grid models is in their simple representation which is profitable especially in computations. The disadvantage of grid models is a fact that they lost information about terrain edges. The size of the smallest object represented by a model depends on resolution of a grid model. Irregularly spaced mass points (ALS Point Cloud) are a source for TIN model generation. Chosen mass points become nods of triangular network, nods are connected by edges and 3 edges form a triangle. A TIN model created directly prom ALS data is too dense. Density can be reduced by removing irrelevant points (omit points on flat terrain). A TIN model better depicts breaklines of terrain as rock edges, dike edges, etc. and formlines of terrain as a ridge lines and valley lines. Density of TIN nods is higher in rugged terrains and on terrain edges.

\subsection{Visualization of DTM}

DTMs are suitable products for many applications like orthorectification of aerial images, flood risk modeling, pedological modeling etc. Archeology and cultural heritage exploration and documentation need suitable visualizations derived from DTM. The most common visualizations of DTMs are hypsometry (Figure $3 \mathrm{a}$ ), contour lines (Figure 3 b), shaded relief (Figure $3 \mathrm{c}$ ) or their combination (Figure $3 \mathrm{~d}$ ). 


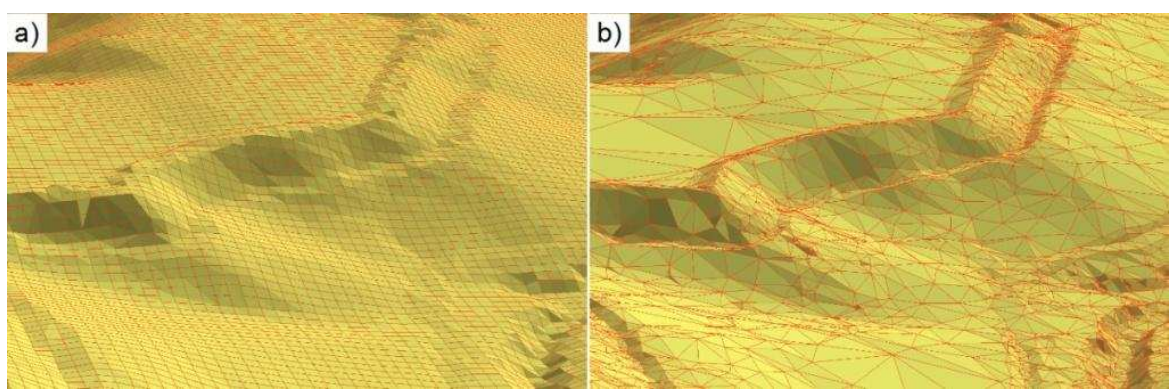

Figure 3: Visualization of DTM (source: archive of Land Survey Office). Left: visualization of grid DTM, right: visualization of TIN DTM
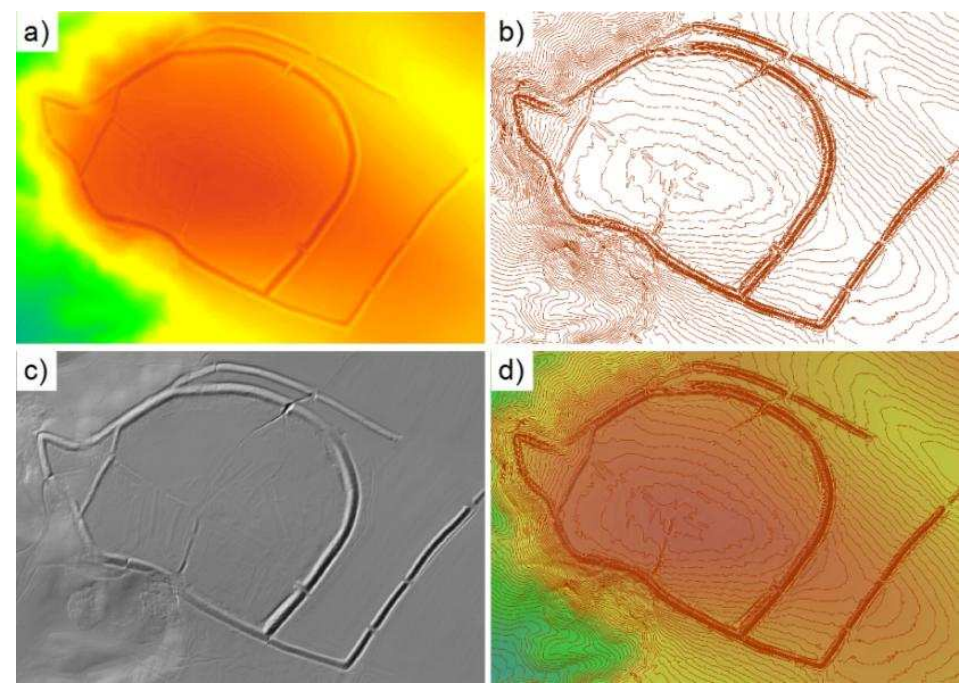

Figure 3: Classical visualizations of elevation data

For archeological purposes shaded relief is the most suitable traditional visualization method of elevation data. It is mostly generated with the illumination azimuth of $315^{\circ}$ (north-west) and the illumination altitude of $45^{\circ}$. Disadvantage of the shaded relief is a fact that linear structures parallel to illumination are not displayed [9]. This problem can be solved by using two shaded reliefs with perpendicular illuminations. Figure 4 a) shows shaded relief illuminated from north-west and Figure 4 b) illuminated from south-west. In Figure 4 a) a linear structure inside the red polygon is obvious; in Figure 4 b) a perpendicular linear structure inside the green polygon is well recognizable.
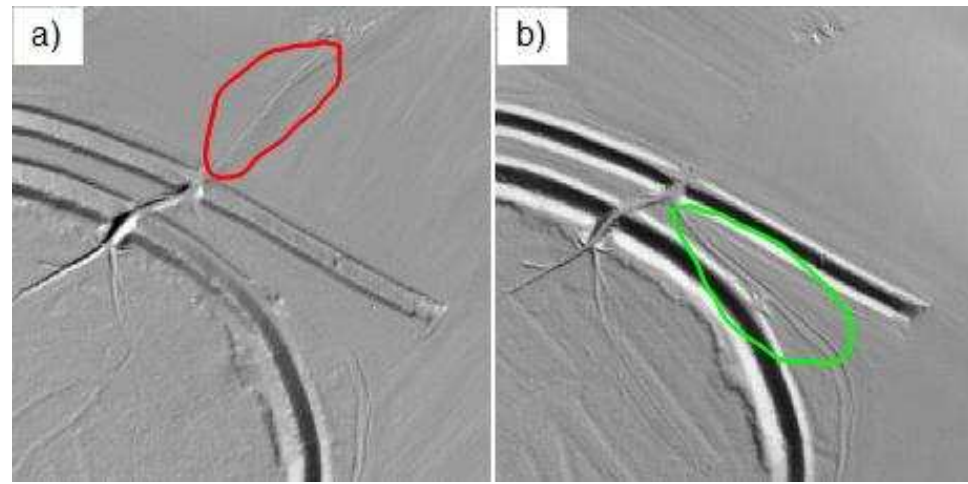

Figure 4: Shaded reliefs with perpendicular illuminations. Left: classical illumination from northwest. Right: illumination from southwest. 
Usage of shaded relief is limited by the illumination azimuth. A combination of shaded relief and terrain slope (Figure 5a) ensures improved visualization in comparison with terrain slope visualization itself mentioned in [9]. A combination of shaded relief and terrain aspect is another possible visualization method (Figure $5 \mathrm{~b}$ ). As it was already mentioned, a different angle of shaded relief illumination shows linear structures in different directions. Shaded relief is represented by gray scale image. A RGB image is composed from three gray scale images. This paper presents color composed shaded relief which is a combination of three shaded relief images (red, green and blue color) illuminated from azimuths $315^{\circ}, 195^{\circ}$ and $75^{\circ}$ (Figure $5 \mathrm{c}$ ). A color composed RGB shaded relief seems to be ideal for archeological exploitation. Color of illuminated surface represents aspect and hue represents slope of terrain.

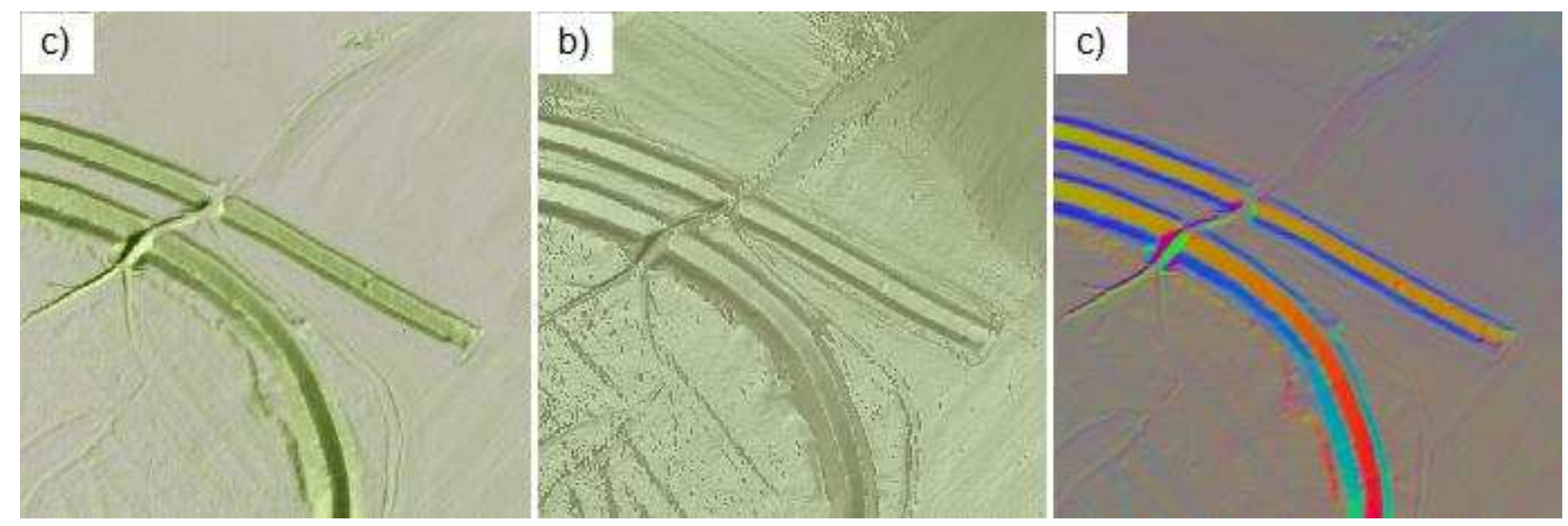

Figure 5: Alternative visualizations of elevation data: a) shaded relief with transparency slope layer, b) shaded relief with transparency aspect layer, c) color composed RGB shaded relief.

\section{EXAMPLES OF DETECTION OF MAN-MADE STRUCTURES IN ELEVATION DATA}

\subsection{Ancient Celtic oppidum}

The Oppidum Vladař is situated in cadastral area of the villages Záhořice and Vladořice in the county of Karlovy Vary. The acropolis is situated on a plateau of the hill elevated about $230 \mathrm{~m}$ above the valley of the river Strela. The Oppidum was constructed gradually in a longer time period. Its global area is $115.3 \mathrm{ha}$, the area of the acropolis is $13.4 \mathrm{ha}$. The residuals of a circumferential fortification defending the acropolis have a form of rampart [10]. Visualization of an orthophoto is on Figure 6 a) and a color composed RGB shaded relief is on Figure 6 b).
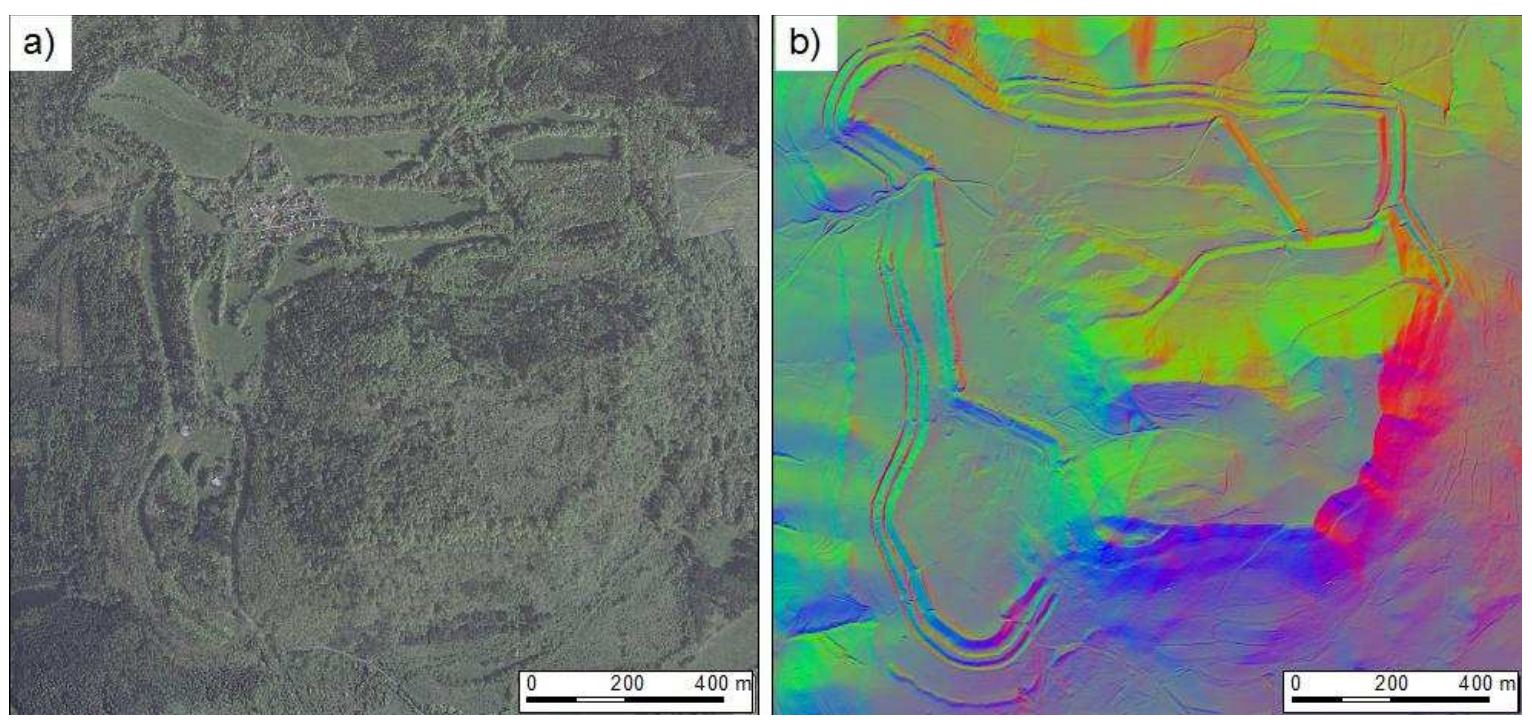

Figure 6: a) Orthofoto and b) Color composed RGB shaded relief of the oppidum Vladar̆ 


\subsection{Medieval mining activities}

At steep slopes of Krušné Hory in the municipality Krupka there are situated many remains of mining activities. As mentioned on official web pages of the municipality [11], first mentions of mining in this region come back to the $10^{\text {th }}$ century. At Figure 7 it is easy to recognize dumps around surface mining pits (the red polygon). In the green polygon there is a linear structure which appears as a fallen underground shaft.

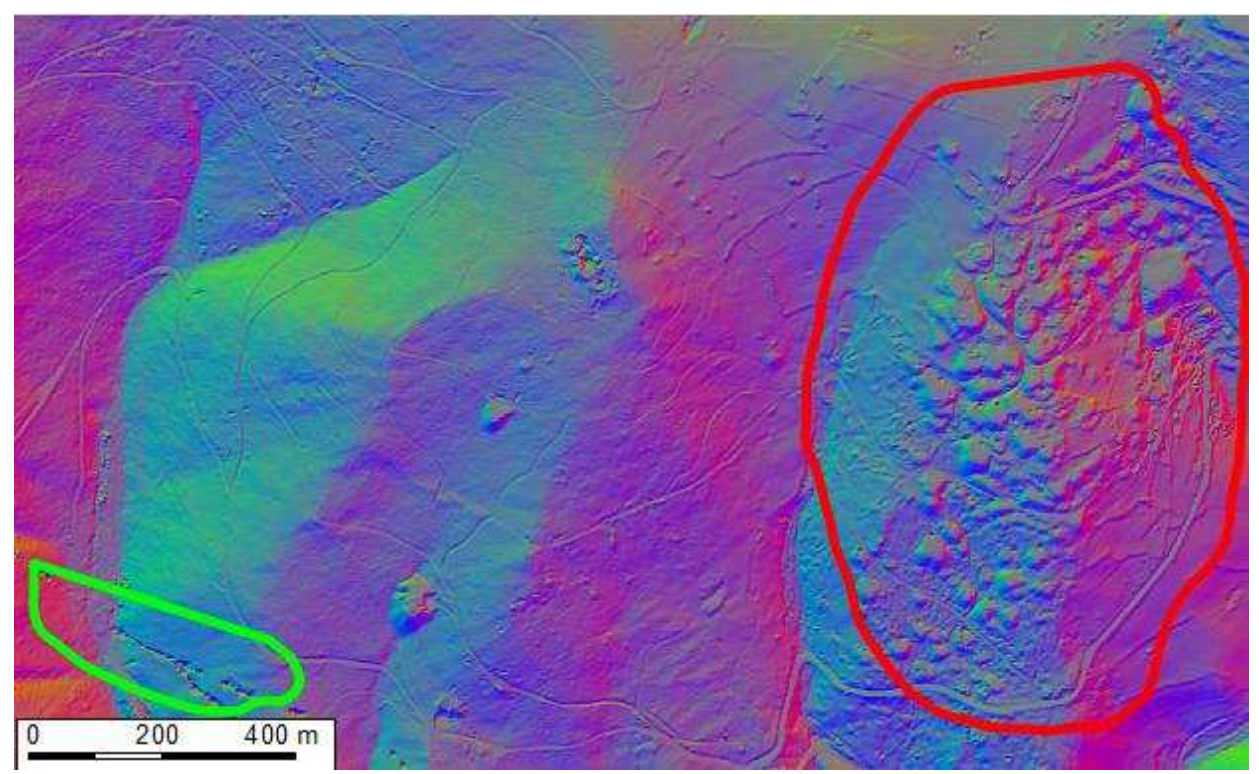

Figure 7: Color composed RGB shaded relief of mining fields near Dolní Krupka

\subsection{Post World War 2 abandoned settlement}

The abandoned settlement Linda (German Lindau) is one of typical examples of historical changes after World War 2 in the border regions of the Czech Republic. According to web pages dealing with perished villages [12], the bordering zone was the reason of the Linda settlement destruction. The number of inhabitants was 173 in 1921 and 11 in 1950 , the number of buildings was 26 in 1921 and 14 in 1950 [12]. In Figure 8 there is visualization of an orthophoto a) and a color composed RGB shaded relief $b$ ) of the abandoned settlement Linda.

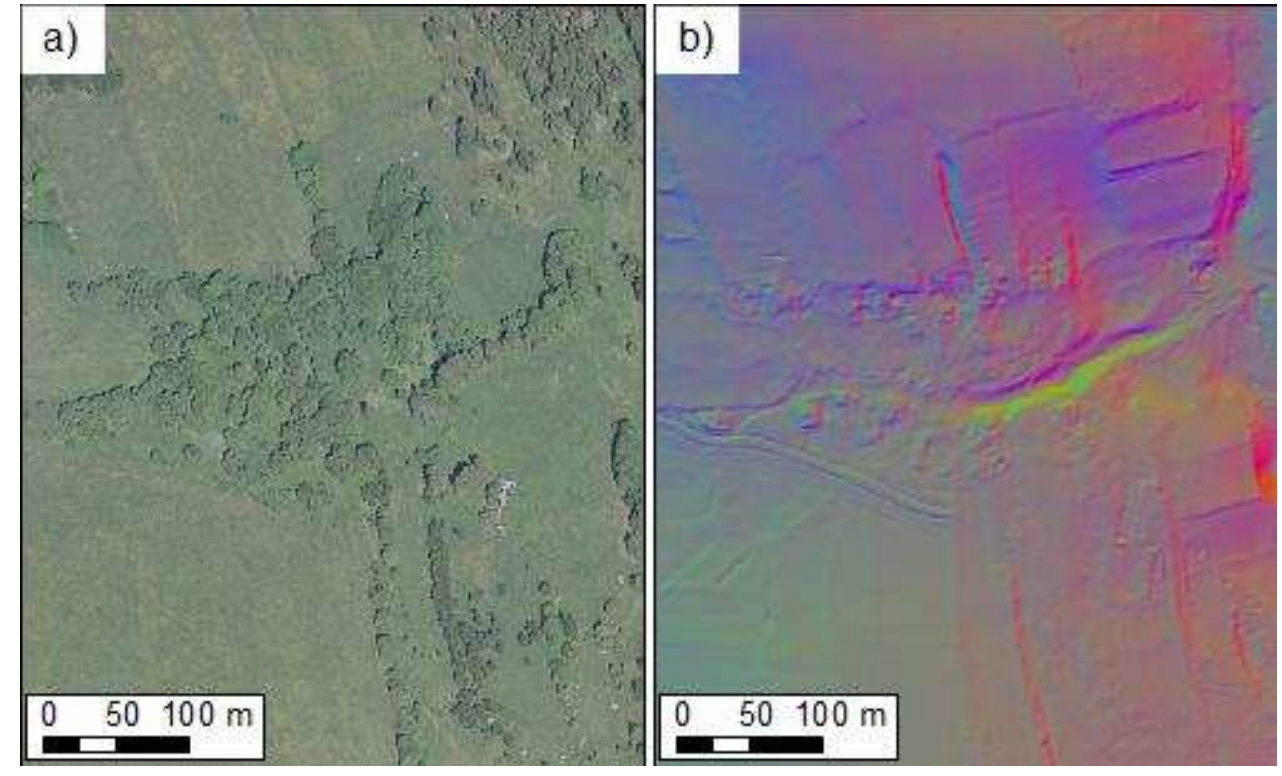

Figure 8: a) Orthophoto and b) Color composed RGB shaded relief of the abandoned settlement Linda 


\section{CONCLUSION}

This paper presents a big potential of ALS data for archaeological investigations. Man-made structures in landscape can be distinguished from natural terrain. It is important to prepare a suitable source of information for man-made structures detection from ALS data. First of all it is necessary to filter out points reflected from nonground objects. The filtration process is necessary for many other applications exploiting elevation data. For archaeology it is crucial to visibly detect significant elevation changes in DTM. For such purposes shaded relief is suitable. To detect structures in all directions it is good to combine shaded relief with slope [9] or aspect. This paper presents new technology of visualization elevation data. This technology is based on composition of three shaded reliefs, each illuminated from different azimuth. By composition is obtained RGB image showing linear structures in all directions. Data density is the only ALS data limiting factor for its usefulness in archaeological prospection. This circumstance is mostly influenced by used scanner, flying height and vegetation season. Data used for this paper is acquired for the whole country in a short period. Mapping in scale 1: 5000 is its basic purpose. The data is not dense enough and not whole data set is taken in ideal vegetation season like in [9]. Nevertheless the ALS data can be an interesting source for archaeological investigation especially in wooded areas.

\section{ACKNOWLEDGMENTS}

I would like to thanks to Land Survey Office of the Czech Republic and to Czech Office for Surveying, Mapping and Cadastre for kind borrow of data and software.

\section{REFERENCES}

[1] Hudak, A.T., Lefsky, M.A., Cohen, W.B., Berterretche, M.: Integration of LiDAR and Landsat ETM+ Data for Estimating and Mapping Forest Canopy Height, Remote Sensing of Environment, 82(2002)2-3, 397-416.

[2] Huising, E.J., Gomes Pereiea, L.M. : Errors and Accuracy Estimates of Laser Data Acquired by Various Laser Scanning Systems for Topographic Applications, ISPRS Journal of Photogrammetry \& Remote Sensing, 53(1998)5, 245-261.

[3] Kašpar, M., Pospíšil, J., Štroner, M., Křemen, T., Tejkal, M.: Laserové skenovaci systémy ve stavebnictní, Praha, Stavební fakulta ČVUT, 2003.

[4] Wehr, A., Lohr, U. (1999): Airborne Laser Scanning - an Introduction and Overview, ISPRS Journal of Photogrammetry \& Remote Sensing, 54(1999)2-3, 68-82.

[5] Wagner, W., Ullrich, A., Ducic, V., Melzer, T., Studnicka, N.: Gaussian Decomposition and Calibration of Novel Small-Footprint Full-Waveform Digitising Airborne Laser Scanner, ISPRS Journal of Photogrammetry \& Remote Sensing, 60(2006)2, 100-112.

[6] Kager, H.: Discrepancies Between Overlapping Laser Scanner Strips - Simultaneous Fitting of Aerial Laser Scanner Strips, International Archives of Photogrammetry and Remote Sensing, 35(2004)B1, 555-560.

[7] Sithole, G., Vosselman, G.: Experimental Comparison of Filtering Algorithms for Bare-Earth Extraction from Airborne Laser Scanning Point Clouds, ISPRS Journal of Photogrammetry \& Remote Sensing, 59(2004), 85-101.

[8] Kraus, K., Pfeifer, N.: Determination of terrain Models in Wooden Areas with Airborne Laser Scanner Data, ISPRS Journal of Photogrammetry \& Remote Sensing, 53(1998)4, 193-203.

[9] Doneus, M., Briese, C.: Full-Waveform Airborne Laser Scanning as a Tool for Archaeological Reconnaissance, Proceedings of the $2^{\text {nd }}$ International Conference on Remote Sensing in Archaeology, Rome, December 2006, 99-106.

[10] Chytráček, M., Šmejda, M.: Opevněný areál na Vladaři a jeho zázemí. K poznání sídelních struktur doby bronzové a železné na horním toku Střely v západních Čechách. Archeologické rozhledy 57(2005), 3-56.

[11] Pavelka,K., Svatušková,J., Bukovinský,M.: Using of VHR satellite data for potential digs localization and their verification using geophysical methods, "1st EARSeL International Workshop on "Advances in Remote Sensing for Archaeology and Cultural Heritage Management”, Rome, 30.9. - 4.10.2008

[12] Pavelka, K. - Pikhartová, L. - Faltýnová, M. - Řezníček, J.: Combining of aerial laser scanning data, terrestrial mobile scanned data and digital orthophoto. Proceedings of 31st ACRS Conference [CD-ROM]. Hanoi: ACRS, 2010, vol. 1, p. 351-356. ISBN 3-11-017708-0

[13] Faltýnová, M. - Pavelka, K.: Mobile laser scanning data combining with aerial laser scanning data and orthophoto. ELMF 2010 Conference Proceedings [CD-ROM]. Nailsworth: Intelligent Exhibitions Ltd, 2010, p. 385391. ISBN 978-0-625-84328-2

[14] http://www.krupka-mesto.czl, 2011-05-24

[15] http://www.zanikleobce.cz/, 2011-05-24 